\title{
The Relation Between Maternal / Neonatal Vitamin D Levels and Early Onset Neonatal Sepsis
}

\author{
Dina Kamal Ali ${ }^{1,}$, , Iman Abdel Mohsen Shaheen ${ }^{2}$ \\ ${ }^{1}$ Department of Pediatrics, Faculty of Medicine, Cairo University, Cairo, Egypt \\ ${ }^{2}$ Department of Clinical Pathology, Faculty of Medicine, Cairo University, Cairo, Egypt \\ Email address: \\ dinakamal_2009@yahoo.com (D. K. Ali),iman.shym@gmail.com (I. A. M. Shaheen) \\ ${ }^{*}$ Corresponding author
}

\section{To cite this article:}

Dina Kamal Ali, Iman Abdel Mohsen Shaheen. The Relation Between Maternal / Neonatal Vitamin D Levels and Early Onset Neonatal Sepsis. American Journal of Pediatrics. Vol. 6, No. 1, 2020, pp. 46-51. doi: 10.11648/j.ajp.20200601.18

Received: January 12, 2020; Accepted: February 17, 2020; Published: February 26, 2020

\begin{abstract}
In addition to its classical role in bone metabolism, vitamin D also has an immunomodulatory effects on immune function. Our aim was to determine the relation between serum 25-hydroxy vitamin $\mathrm{D}(25(\mathrm{OH}) \mathrm{D})$ concentrations in newborns and their mothers with early onset neonatal sepsis (EOS). Also we aim to study the effect of severity of vitamin D deficiency on incidence of EOS. The design comprises a hospital- based case- control study. The study group consisted of 50 newborns with EOS who was admitted to neonatal intensive care unit and their mothers. Controls were 50 healthy newborns of the same age as the study group and their mothers. The study subjects were divided into insufficient, moderate and severe deficiency according to vitamin D level. There is no significant statistical difference between study and control groups in gestational week, birth weight, birth height, head circumference and age. The mean serum $25(\mathrm{OH}) \mathrm{D}$ concentrations in the study group newborns were significantly lower than those of the control group $(11.58 \pm 4.883 \mathrm{ng} / \mathrm{ml}$ and $28.78 \pm 6.453 \mathrm{ng} / \mathrm{ml}$ respectively). The $25(0 \mathrm{H}) \mathrm{D}$ concentrations of newborns were highly correlated with mothers' serum in both groups. Severe vitamin D deficiency was significantly more common in the sepsis group. Data shows that $25(\mathrm{OH}) \mathrm{D}$ concentrations of the newborns were highly correlated with the level of CRP, duration of hospital stay, and complications caused by sepsis. Our findings suggest that newborns with vitamin D deficiency may have an increased risk of suffering from EOS. Newborns with more vitamin D deficiency were found to have higher CRP levels, a longer hospital stay, and a higher incidence of complications. The strong positive correlation between newborns' and their mothers' $25(\mathrm{OH}) \mathrm{D}$ concentrations makes that adequate vitamin D supplementation of mothers during pregnancy is of great importance, through a proper ante-natal care, especially in winter months.
\end{abstract}

Keywords: Neonatal, Vitamin D, Early Onset Sepsis

\section{Introduction}

Vitamin D deficiency is a worldwide complication with prevalence ranging from $18-84 \%$ that is more dependent upon geographic region, ethnicity, type of clothing and dietary intake. The main role of vitamin D in the body is to make sure there is enough calcium and phosphate to keep the bones healthy and strong [1]. In addition to this classical role in bone metabolism, vitamin $\mathrm{D}$ also has immunomodulatory effects on immune function [3].

Vitamin D has also been found to have some neonatal protective properties against infectious diseases by regulating of the innate-adaptive immune system, anti-inflammatory effects, increased monocyte responses, and enhanced mucosal barrier as well as by endothelial function [15-26]. There is close and deep relationship between maternal and fetal vitamin D [29].

Maternal vitamin D status in pregnancy affects the status of the infant for the first few months of life. If maternal vitamin D status is good during the last stages of pregnancy the newborn child should have adequate vitamin D status for sometime after birth in the absence of significant input from $\operatorname{diet}[4]$.

Early onset neonatal sepsis is a clinical syndrome characterized by sign and symptoms of infection with or 
without bacteremia in the first 5-7 days of life which is still an important cause of morbidity and mortality among infants [23].

Although some studies reported a link between vitamin D deficiency and critical illness in adults, a direct relationship has not been directly shown yet. However, few studies evaluated the association between early onset sepsis (EOS) and maternal/neonatal vitamin D levels.

The objective of this prospective study is to determine the possible role of maternal and neonatal plasma vitamin D levels on EOS development in term infants. We also aim to study the effect of severity of vitamin D deficiency on incidence of EOS.

\section{Study Design}

This is a prospective case-control study that included 50 term infants, who will be admitted to neonatal care unit in Children's Hospital, Cairo University, Egypt with clinical and laboratory findings of early onset sepsis, from January 2013 to May 2014.

Sepsis Criteria defined by Gitto et al [8]

Highly probable sepsis at least three sepsis-related clinical signs, CRP $>1$ mgdl-1, with two or more other related serum parameters in addition to CRP, Blood culture positive or negative. Probable Sepsis less than 3 sepsis related signs, CRP $>1$ mgdl-, at least two other altered serum parameters in addition CRP. Possible Sepsis less than 3 sepsis related clinical sign, $\mathrm{CRP}<1 \mathrm{mgdl}-1$, Less than 2 other altered serum parameter, Blood culture negative.

Clinical signs of sepsis: respiratory (distress, apnea, tackypnea, or hypoxia), cardiological (tachycardia or bradycardia), hemodynamics (bad color, por peripheral hypoperfusion, hypotension), neurological (irritability, lethargy, hypotonia, hypo activity, seizures), gastrointestinal (poor feeding, abdominal distension, feeding intolerance), temperature (fever $>38 \mathrm{c}$, hypothermia $<36 \mathrm{c}$ ), metabolic (acidosis or hyperglycemia).

The study group will consist of 50 term neonates who are clinically suspected to have an early infection from the first day of life. Blood for neonatal and maternal vitamin D levels will be obtained from all infants and their mothers at the time of hospital admissions. Only infants with high probable sepsis will consist the study group. For this group at time of admission CBC differential, CRP, and blood culture will be done, and it will be repeated after 48 hours. Complications caused by sepsis (respiratory distress, tachycardia, dehydration, meningitis, ets.....), and duration of hospital stay will be also recorded.

Fifty healthy neonates, with no prenatal risk factor for early onset sepsis were enrolled in the study as a Control group.

In both groups, maternal samples will be obtained at the postpartum period at the time of neonates' hospitalization. Newborn's gestational ages, birth weight, birth height, and birth head circumference were elicited from health records brought by parents. Also recorded was whether the newborns were breastfeeding or not.

The severity of vitamin D deficiency will be related to neonatal sepsis. Neonates will be divided into three groups in terms of insufficient, moderate and severe vitamin D deficiency according to maternal and neonatal vitamin D levels and a possible association between vitamin D deficiencies and clinical/laboratory proven sepsis will be investigated.

Both genders are included in the study, age up to 72 hours.

Venous blood specimens were collected from all neonates included in the study, and their mothers. The serum samples were stored at $-20 \mathrm{c}$ and protected from direct exposure to sunlight until the analysis. For the quantitative determination of $25(\mathrm{OH})$ D concentrations in the serum samples, a commercially available 25-hydroxy vitamin D3 RIA (specific radioimmunoassay) kit (BIOSOURCE Catalog No. KIP1961, Nivelles, Belgium) was used according.

For levels of vitamin D less than $40 \mathrm{ng} / \mathrm{ml}$ is considered insufficiency, while levels less than $20 \mathrm{ng} / \mathrm{ml}$ is considered deficiency according to institute of medicine (IOM) report and the consensus report on nutritional rickets [22, 24, 25].

Insufficient: $20-40 \mathrm{ng} / \mathrm{ml}$

Moderate deficiency: 10-20 ng/ml

Severe deficiency: $<10 \mathrm{ng} / \mathrm{ml}$

Infants were treated with appropriate antibiotic therapies including ampicillin in combination with gentamicin for the first-line therapy of EOS used in the hospitals of Egypt. Neonates with positive cultures were treated with antibiotics according to the causative organisms detected by the culture. The antimicrobial therapy was stopped after clinical and laboratory improvement.

The study was approved by the local research ethics committee of Cairo university Hospital for children and written informed consents were obtained from the parents of all neonates to share in the study.

\section{Statistical Analysis}

Data were statistically described in terms of mean \pm standard deviation $( \pm \mathrm{SD})$, median and range, or frequencies (number of cases) and percentages when appropriate. Comparison of numerical variables between the study groups was done using Student $\mathrm{t}$ test for independent samples in comparing 2 groups when normally distributed and Mann Whitney U test for independent samples when not normally distributed. Comparison of Numerical variables between more than two groups was done using Kruskal Wallis test with Mann Whitney test as a posthoc multiple 2-group comparison. For comparing categorical data, Chi square $\left(\chi^{2}\right)$ test was performed. Exact test was used instead when the expected frequency is less than 5. Correlation between various variables was done using Pearson moment correlation equation for linear relation in normally distributed variables and Spearman rank correlation equation for nonnormal variables and or non-linear monotonic relations. $p$ values less than 0.05 was considered statistically significant. All statistical calculations were done using computer 
program SPSS (Statistical Package for the Social Science; SPSS Inc., Chicago, IL, USA) release 15 for Microsoft Windows (2006).

\section{Results}

In this study, 50 (27 males, 23 females) cases and 50 controls (26 males, 24 females) were involved. There was no significant difference in postnatal mean age between case and control groups (10.9 \pm 9.2 day and $9.6 \pm 7.06$ day, respectively, $\mathrm{p}=0.234)$. The anthropometric characteristics of newborns are shown in Table 1. As the table shows, there is no significant statistical difference between study and control groups in gestational week, birth weight, birth height, and head circumference. All cases were exclusively breast-fed. The number of mothers in the study group who never used vitamin D supplementation (23 mothers, $46 \%$ of the study group) was significantly higher than that in the control group ( 8 mothers, $16 \%$ of the control group) $(p<0.05)$.

Table 1. Birth anthropometric measures and gestational age of new-borns.

\begin{tabular}{llll}
\hline Birth mean (s. d.) & Study group & Control group & p-value \\
\hline Weight $(\mathrm{g})$ & $3150.0(569.66)$ & $3135.0(422.7)$ & 0.900 \\
Length $(\mathrm{cm})$ & $49.15(2.99)$ & $49.79(1.31)$ & 0.408 \\
Head circumference (cm) & $34.16(1.78)$ & $34.71(1.16)$ & 0.317 \\
Gestational age (week) & $39.17(1.68)$ & $39.23(0.78)$ & 0.659 \\
\hline
\end{tabular}

$\mathrm{P}>0.05$ no significant difference observed.

The mean serum $25(\mathrm{OH}) \mathrm{D}$ concentrations in the study group newborns were lower than those of the control group $(11.58 \pm 4.883 \mathrm{ng} / \mathrm{ml}$ and $28.78 \pm 6.453 \mathrm{ng} / \mathrm{ml}$ respectively) with a high statistical significant value $p=0.000$. The majority $(81 \%)$ of infants in the sepsis group had a mean 25 $\mathrm{OHD}<11 \mathrm{ng} / \mathrm{ml}$. Also mean serum 25(OH) D concentrations in the mothers of the study group were lower than in the mothers of the control group $(21.98 \pm 8.925$ and $44.78 \pm 7.407$ respectively) with a high statistical significant value $\mathrm{p}=0.000$.

The $25(0 \mathrm{H}) \mathrm{D}$ concentrations of newborns were highly correlated with mothers' serum levels $(r=0.79, p<0.05)$ in the study group. The correlation between 25(OH)D concentrations in newborns and their mothers in control group is also considerable $(\mathrm{r}=0.53 ; \mathrm{p}<0.05)$.

It was noticed that both maternal and neonatal 25-OHD levels were significantly higher in the summer months and with regular exposure to sunlight (mean 24.3 $\pm 21 \mathrm{ng}$ dl compared to $13.6 \pm 10.8$ in winter months) $\mathrm{p}<0.05$.

The data showed that, 46 patients $(46 \%)$ had severe vitamin D deficiency $(<10 \mathrm{ng} / \mathrm{dl})$, while 8 patients $(8 \%)$ had moderate deficiency $(10-20 \mathrm{ng} / \mathrm{dl})$, and 21 patients $(21 \%)$ showed vitamin D insufficiency (20-40 ng/dl), while 25 patients $(25 \%)$ have normal level of vitamin D all in the control group. Table 2 shows detailed information about the distribution of vitamin $\mathrm{D}$ level among the newborns of the two groups and their mothers.

Table 2. Serum $25(\mathrm{OH}) D$ distribution of newborns and their mothers.

\begin{tabular}{llll}
\hline $\mathbf{2 5}(\mathbf{O H}) \mathbf{D}(\mathbf{n g} / \mathbf{m l})$ & Study group, $\mathbf{N}=\mathbf{5 0}(\mathbf{\%})$ & Control group, $\mathbf{N}=\mathbf{5 0}(\mathbf{\%})$ & Total $\mathbf{N = 1 0 0}(\mathbf{\%})$ \\
\hline Newborns & & & \\
Severe deficiency & $40(80.0)$ & $6(12.0)$ & $46(46.0)$ \\
Moderate deficiency & $6(12.0)$ & $2(4.0)$ & $8(8.0)$ \\
Insufficiency & $4(8.0)$ & $17(34)$ & $25(21.0)$ \\
Normal & $0(0.0)$ & $25(50.0)$ & \\
Mothers & & & $39(39.0)$ \\
Severe deficiency & $32(64.0)$ & $7(14.0)$ & $14(14.0)$ \\
Moderate deficiency & $10(20.0)$ & $4(8.0)$ & $37(37.0)$ \\
Insufficiency & $8(16.0)$ & $29(58.0)$ & $10(10.0)$ \\
Normal & $0(0.0)$ & $10(20.0)$ & \\
\hline
\end{tabular}

Table 3 shows the relation between CRP level, duration of hospital stay, complications caused by sepsis, and severity of vitamin $\mathrm{D}$ deficiency.

Data shows that $25(\mathrm{OH}) \mathrm{D}$ concentrations of newborns and their mothers were highly correlated with the level of CRP, duration of hospital stay, and complications caused by sepsis $(\mathrm{r}=0.425, \mathrm{r}=0.512, \mathrm{r}=0.524$ respectively $) \mathrm{p}$ for all $<0.05$.

Table 3. The relation between CRP levels, hospital stay, complications and severity of vitamin D deficiency.

\begin{tabular}{lllll}
\hline & CRP1 (mean \pm st) & CRP2 (mean \pm st) & Hospital stay (mean \pm st) & ComplicationsNo. of cases (\%) \\
\hline Severe deficiency & $19.00 \pm 10.296$ & $53.75 \pm 18.301$ & $15.00 \pm 8.246$ & $29(58)$ \\
Moderate deficiency & $11.54 \pm 3.799$ & $51.00 \pm 17.263$ & $11.85 \pm 5.610$ & $13(26)$ \\
Insufficiency & $5.75 \pm 1.708$ & $23.75 \pm 7.089$ & $6.40 \pm 2.160$ & $8(16)$ \\
\hline
\end{tabular}

Cases with cultural proven sepsis were much higher in the study group than those in the control group (16 cases in the study group, compared to 5 cases in the control group), with the predominance of $\mathrm{E}$. coli in positive cases. $(\mathrm{p}=0.009)$.

\section{Discussion}

The main aim of our study is to detect the levels of vitamin 
$\mathrm{D}$ in both groups, and determine its relation to the development of neonatal sepsis. We find that serum $25(\mathrm{OH})$ $\mathrm{D}$ concentrations in newborns with neonatal sepsis (study group) were lower than those of the healthy newborns (control group) and most newborns who have the serum $25(\mathrm{OH}) \mathrm{D}<11 \mathrm{ng} / \mathrm{ml}$ were more likely to develop sepsis. The study also showed that the mean $25(\mathrm{OH}) \mathrm{D}$ concentrations in mothers of the study group were lower than those of the control group. Levels of 25-OHD were also higher in summer and with regular vitamin $\mathrm{D}$ supplementation. Furthermore, it was found that $25(\mathrm{OH}) \mathrm{D}$ concentrations of newborns are highly correlated with $25(\mathrm{OH}) \mathrm{D}$ concentrations of their mothers in both the study and control groups. It was found also that degree of severity of vitamin D deficiency is highly correlated with level of CRP, duration of hospital stay, and complications caused by sepsis.

These results were in agreement with the study done by Cetinkaya [5], who stated that maternal and neonatal 25OHD levels were significantly lower in term infants who were admitted with EOS. Neonatal 25-OHD levels were positively correlated with maternal 25-OHD levels.

Also these results were in agreement with the result of the study done by Karatekin [16], who was studying the effect of vitamin D deficiency on the development of lower respiratory infections.

These findings are important because they show that newborns with vitamin D deficiency may have an increased risk of suffering from EOS, and the EOS is common cause of morbidity and mortality in newborn period, especially in developing countries [30].

Valdivielso [28] provided one of the earliest studies that suggested that vitamin D could up regulate the production of anti-microbial peptides. They demonstrated that $1,25(\mathrm{OH}) 2 \mathrm{D} 3$ treatment up-regulated cathelicidin mRNA in several cell lines and primary cultures including keratinocytes, neutrophils, and macrophages.

Baeke [2] stated that, vitamin D has a physiological role beyond its well -known role in skeletal homeostasis. Vitamin $\mathrm{D}$ as an immunomodulatory targeting various immune cells, including monocytes, macrophages, dendritic cells (DCs), as well as T-lymphocytes and B-lymphocytes, hence modulating both innate and adaptive immune responses. Besides being targets, immune cells express vitamin Dactivating enzymes, allowing local conversion of inactive vitamin $\mathrm{D}$ into $1,25(\mathrm{OH}) 2 \mathrm{D} 3$ within the immune system.

In addition to systemic inflammatory response modulation, vitamin D also has effects on the local control of pathogens. Vitamin D was reported to inhibit the growth of and/or killed strains of Staphylococcus aureus, S. pyogens, k. pneumoniae, and E. coli. Many examples document the benefits of having an optimal vitamin $\mathrm{D}$ level in gram negative bacteria. Treatment with $25(\mathrm{OH}) \mathrm{D}$ protected $3 \mathrm{~A}$ cells of the placenta against cell death after infection with $\mathrm{E}$. coli [20].

In recent years, vitamin $\mathrm{D}$ was reported to have a complex effect on immune functions as it enhanced innate immunity while it also downregulated the acquired immune responses $[7,18]$. The mechanical barrier of the skin and other epithelial surfaces constitute the first barrier to infections and activated 25- $\mathrm{OH}$ vitamin $\mathrm{D}$ has an important role in maintaining the integrity of epithelial cells by encoding the protiens needed for several tight junctions [31].

Vitamin D induce down regulation of the cytokine response. Th1 cytokine profile is vital for clearance of certain organisms and ancillary immune activity, and a limiting effect on this cytokine profile may result in reduced chances for overcoming infections. This fact can explain why patients with vitamin D deficiency have longer stay in the hospital, higher CRP levels, and more incidences of complications due to spreading of infections [12].

This indicates the economic burden due to vitamin D deficiency in newborns on family and community. This economic burden is a short term one. Considering that vitamin D deficiency can lead to chronic diseases in long term, the economic burden of vitamin D deficiency in long term would be much more. Hence, the main implication of the study is that decreasing the vitamin D deficiency in newborns may reduce their morbidity risk. Studies are needed in this direction as well.

A study done by Moller, et al [23] investigated the prevalence of vitamin D deficiency in critically ill children admitted to the pediatric intensive care unit, a high rate of vitamin D deficiency was present among critically ill children and was associated with greater severity of critical illness. However, to the best of our knowledge, there are few studies investigated the association between neonatal sepsis and maternal/neonatal 25-OHD levels in both term and preterm infants in North Africa.

Similar to other investigations done by $[4,19,5]$, our study showed that the blood $25(\mathrm{OH}) \mathrm{D}$ concentrations in the neonates correlated well with the maternal $25(\mathrm{OH}) \mathrm{D}$ concentrations. Yang et al. demonstrated that mothers and their neonates with early onset sepsis had lower 25-OHD levels in comparison with their counter-parts in the control group, leading to the neonatal early-onset sepsis risk for fullterm infants [34]. Karras et al. stated that maternal vitamin D level has been found to be potentially linked to a decrease risk of neonatal infectious diseases including respiratory infections and sepsis [17]. This important correlation between the concentration of $25(\mathrm{OH}) \mathrm{D}$ in the mothers and their newborns, make regular intake of vitamin D during pregnancy, is of utmost importance. This can be achieved through careful antenatal care and proper educational programs for the mothers about the role of vitamin D in the development of immunity of their kids.

\section{Conclusion}

Our study concluded that lower vitamin D levels is associated with higher incidence of neonatal sepsis. Neonates with lower vitamin D levels have recorded longer stay in the hospital, with more incidences of complications and higher CRP levels. Vitamin D concentrations in the neonate were well correlated with their mothers. 


\section{Authors Contributions}

DK, I SH, conceived the study, interpreted the data, and critically revised the reports and obtained clinical information from study participants. All authors read and approved the final manuscript.

\section{Funding}

The authors received no specific funding for this work.

\section{Availability of Data and Materials}

The datasets used and analyzed during the current study are available from the corresponding author on reasonable request.

\section{Conflict of Interest}

The authors declare no conflict of interest.

\section{Acknowledgements}

No.

\section{References}

[1] Aarras SN, Shah I, Petroczi A, Goulis DG, Bili H, 2013biomedcentral.com. An observational study reveals that neonatal vitamin $\mathrm{D}$ is primarily determined by maternal contributions.

[2] Baeke F, Takiishi T, Korf H, Gysemans C, Mathieu C. Vitamin D: modulator of the immune system. Curr Opin Pharmacol 2010 Aug; 10 (4): 482-96.

[3] - Barnett ED, Klein JO (2006). Bacterial infections of the respiratory tract. In: Remington JS, Klein JO, Wilson CB, Baker CJ (eds). Infectious Diseases of the fetus and newborn infant. WB Saunders Philadelphia, pp 297-316.

[4] Bodnar LM, Simhan HN, Powers RW, Frank MP, Cooperstein E, Roberts JM (2007). High prevalence of vitamin D deficiency in black and white pregnant women residing in the northen United States and their neonates. J Nutr 137, 447-452.

[5] Cetinkaya M, Cekmez F, Buyukkale G, Erener-Ercan T, Demir F, Tunc T, Aydin N and G Aydemir. Lower vitamin D levels are associated with increased risk of early onset neonatal sepsis in term infants. Journal of perinatology (2015) $35,39-45$.

[6] Cetinkaya M, Kanuni Sultan Suleyman Training and Research 2013. Comparison of maternal and neonatal vitamin D levels in term neonates with/ without early onset sepsis.

[7] Di Rosa M, Malaguarnera M., Nicoletti F., Malaguarnera L. $25 \mathrm{OH}$ Vitamin D3: A helpful immune-modulator. Immunology. 2011; 134: 123-139. Doi: 10.1111/j.13652667.2011.03482.x.

[8] Gitto E, Karbownik M, Reiter RJ, Tan DX, Cuzzocrea S, Chiurazzi $\mathrm{P}$ et al. effect of melatonin treatment in septic newborns. Pediatr Res 2011; 50: 756-760.
[9] Grant WB, Garland CF, Holick MF (2005). Comparison of estimated economic burdens due to insfficient solar ultraviolet irradiance and vitamin D and excess solar UV irradiance for the United States. Photochem photobiol 81, 1276-1286.

[10] Grant WB, Holick MF (2005). Benefits and requirements of vitamin D for optimal health: a review. Altern Med Rev 10, 94-111.

[11] Holick MF (2004). Sunlight and vitamin D for bone health and prevention of autoimmune diseases, cancers, and cardiovascular disease. Am J Clin Nutr 80 (Suppl, 6), s1752s1688.

[12] Hollis BW (2005). Circulating 25-hydroxy vitamin D levels indicative of vitamin D sufficiency: implications for establishing a new effective dietary intake recommendation for vitamin D. J Nutr 135, 317-322.

[13] Hollis BW, Wagner CL (2004). Vitamin D requirements during lactation: high-dose maternal supplementation as therapy to prevent hypovitaminosis D for both the mother and the nursing infant. Am J Clin Nutr 80 (suppl, 6), S1752-1758.

[14] Hollis BW, Wagner CL (2006). Vitamin D deficiency during pregnancy: an ongoing epidemic. Am J Clin Nutr 84, 273.

[15] Jeng L, YamshchikovAV, Judd S. Alterations in vitamin Dstatus and anti-microbial peptide levels in patients in the intensive care unit with sepsis. J Transl Med, 2009; 7: 28.

[16] Karatekin G, Kaya A, Salihoglu O, Balci H, Nuhoglu A. Association of subclinical vitamin D deficiency in newborns with acute lower respiratory infection and their mothers. European Journal of Clinical Nutrition (2009) 63, 473-477.

[17] karras SN, Fakhoury H, Muscogiuri G. Maternal vitamin D levels during pregnancy and neonatal health: evidence to date and clinical implications. The Adv Musculoskelet Dis. 2016; 8: $124-35$.

[18] Kempker J. A., Han J. E., Tangpricha V., Ziegler T. R., Martin G. S. 25- OH Vitamin D and sepsis: An emerging relationship. Dermato-endocrinol. 2012; 4: 101-108. dio: 10.4161/derm. 19859 .

[19] Lee JM, Smith JR, Philipp BL, Chen TC, Mathiue J, Holick MF (2007). Vitamin D deficiency in a healthy group of mothers and newborn infants. Clin Pediatr (phila) 46, 42-44.

[20] Liu N, Kaplan AT, Low J, Nguyeny L, Liu GY, Equils O. Vitamin D induces innate antibacterial responses in human trophoblasts via an intracrine pathway. Boil Reprod 2009; 80: 398-406.

[21] Madden K, Feldman HA, Smith EM, Gordon CM, Keisling SM, Sullivan RM et al. vitamin D deficiency in critically ill children. Pediatrics 2012; 130: 421-428.

[22] Manson J. E., Brannon P. M., Rosen C. J., Taylor C. L. Vitamin D Deficiency- Is There Really a Pandemic? N. Engl. J. Med. 2016; 375: 1817-1820.

[23] Moller S, Laigaard F, Olgaard K, Hemmingsen C. Effect 1,25dihydroxy-vitamin D3 in experimental sepsis. Int J Med Sci 2007; 4: 190-195.

[24] Munns C. F., Shaw N., Kiely M, Specker B. L., TGlobal Consensus Recommendations on Prevention and Management of Nutritional Rickets. J. Clin. Endocrinol. Metab. 2016; 101: 394-415. Doi: 10.1210/jc.2015-2175. 
[25] Ross A. C., Manson J. E., Abrams S. A., Aloia J. F., Brannon P. M., Clinton S. K., Durazo- Arvizu R. A., Gallagher J. C., Gallo R. L., Jones G., et al. the 2011 Reports on Dietary Reference Intakes for Calcium and Vitamin D from the Institutes of Medicine: What clinicians need to know. J. Clin. Endocrinol. Metab. 2011; 96: 53-58. doi: 10.1210/jc.20102704.

[26] Say B, Uras N, Sahin S. Effects of cord blood vitamin D levels on the risk of neonatal sepsis in premature infants. Korean, J Pediatr. 2017; 60: 248-53.

[27] Schrag SJ, Stoll BJ: Early-onset neonatal sepsis in the era of widespread intrapartum chemoprophylaxis. Pediatr Infect Dis J 2006; 251: 259 .

[28] Valdivielso JM, Fernandez E (2006). Vitamin D receptor polymorphisms and diseases. Clin Chim Acta 371, 1-12.

[29] Von Websky, Hasan AA, Reichetzeder C, et al. Impact of vitamin $\mathrm{D}$ on pregnancy-related disorders and on offspring outcome. J Steroid Biochem Mol Biol. 2018; 51-64.

[30] Wang TT, Nestel FB, Bourdeau V, Nagi Y, Wang Q, Liao J et al. (2004). 1,25-Dihydroxyvitamin D3 is a direct inducer of antimicrobial peptide gene expression. J Immunol 173, 29092912.

[31] Watkins R. R., Lemonovich T. L., Salata R. A. An update on the association of Vitamin D deficiency with common infectious diseases. Can. J. Physiol. Pharmacol. 2015; 93: 363368. Doi: 10.1139/cjpp-2014-03520.

[32] World Health Report 2005: http://www.who.int/whr/2005/annex/en/index.html.

[33] Yamshchikov AV, Desi NS, Blumberg HM, Ziegler TR, Tangpricha V. Vitamin D for treatment and prevention of infectious diseases: a systemic review of randomized controlled trials. Endocr Pract. 2009; 15 (5): 438-449.

[34] Yang LR, Li H, Yang TY, et al. relationship between vitamin $\mathrm{D}$ defiency and early onset neonatal sepsis. Zhongguo Dang Dai Er Ke Za Zhi. 2016; 18: 791-5.

[35] Youssef DA, Miller CW, El-Abbassi AM, Cutchin DC, Cutchins C, Grant WB et al. antimicrobial implications of vitamin D. dermoendocrinol 2011; 3: 220-3229. 